\title{
On-Ramping to Academia: Women's Experiences of Transitioning from Nonaca- demic to Academic Careers
}

\section{Dr. Coleen Carrigan, Cal Poly San Luis Obispo}

Professor Coleen Carrigan is a feminist anthropologist and an Assistant Professor of Gender, Race, Culture, Science and Technology Studies at Cal Poly San Luis Obispo. She investigates the historical and cultural dimensions of underrepresented groups' participation in science, technology and engineering and the reasons why white males still dominate these fields.

\section{Prof. Eve A. Riskin, University of Washington}

Eve Riskin received her BS degree in Electrical Engineering from M.I.T. and her graduate degrees in EE from Stanford. Since 1990, she has been in the EE Department at the University of Washington where she is now Associate Dean of Diversity and Access in the College of Engineering, Professor of Electrical Engineering and Director of the ADVANCE Center for Institutional Change. With ADVANCE, she works on mentoring and leadership development programs for women faculty in SEM. Her research interests include image compression and image processing, with a focus on developing video compression algorithms to allow for cell-phone transmission of American Sign Language. She was awarded a National Science Foundation Young Investigator Award, a Sloan Research Fellowship, the 2006 WEPAN University Change Agent award, the 2006 Hewlett-Packard Harriett B. Rigas Award, and the 2007 University of Washington David B. Thorud Leadership Award. She is a Fellow of the IEEE.

\section{Kathleen O'Leary, University of Washington}

Katie O'Leary is a PhD student at the University of Washington Information School. She has worked with Dr. Eve Riskin as part of the ADVANCE Center for Institutional Change to understand the experiences of underrepresented minorities in STEM. Her dissertation work focuses on the perspectives, goals, and values of people seeking support for mental wellness. A major focus of her research is developing a method that can facilitate making design tradeoffs to support personal values. In addition to working with Dr. Wanda Pratt's iMed group, Katie works with Jacob Wobbrock as part of his Mobile Accessible Design Lab.

\section{Dr. Joyce Yen, University of Washington}

Dr. Joyce W. Yen is the Program/Research Manager for the University of Washingtons ADVANCE Center for Institutional Change (UW ADVANCE). In this role, she provides faculty professional development on a campus and national scale and does a variety of work to advance diversity in science and engineering at the faculty level. Her diversity and faculty work has received over $\$ 4.5$ million in grant funding. Dr. Yen was previously an assistant professor in Industrial Engineering at the University of Washington, Seattle. She received her M.S. and Ph.D. in Industrial and Operations Engineering from the University of Michigan, Ann Arbor. She received her B.S. in Mathematics from the University of Nebraska-Lincoln, graduating from the Honors Program and summa cum laude.

\section{Ms. Priti N Mody-Pan, University of Washington}

Priti N. Mody-Pan is the Deputy Director and Director of Evaluation at the Center for Workforce Development. She leads program evaluations, develops proposals and new contracts, and conducts research on diversity in science and engineering. Ms. Mody-Pan received her Master of Public Administration (MPA) and Master of Arts in International Studies (MAIS) degrees from the University of Washington and her BA in Political Science and East Asian Studies at Washington University in St. Louis.

\section{Dr. Matthew O'Donnell, University of Washington}

Frank and Julie Jungers Dean Emeritus and a Professor of Bioengineering at the University of Washington. 


\section{On-Ramping to Academia: \\ A National Workshop for Women Transitioning from Nonacademic to Academic Careers}

In 2008, the University of Washington's ADVANCE Center for Institutional Change received a National Science Foundation (NSF) ADVANCE Partnerships for Adaptation, Innovation, and Dissemination grant called "On-Ramps into Academia." (http://www.engr.washington.edu/onramp/)

The goal of On-Ramps into Academia was to increase the pool of women faculty available to all universities by providing professional development to $\mathrm{PhD}$-level women in industry or research laboratories who wished to transition into faculty positions. Unlike the more traditional strategy of institutions recruiting female faculty from other universities to increase the number of female faculty in science and engineering departments, this strategy increases the number of female faculty nationally. On-Ramps is a new approach to faculty recruitment. $\mathrm{PhDs}$ in science and engineering can leverage their nonacademic skills and experiences into successful careers as faculty members.

Interviews with On-Ramps into Academia workshop participants revealed three core barriers that can influence the viability of transitioning to academia, particularly for women. We also discovered that the new career also has major rewards for those who make the transition. We next describe the On-Ramps workshops and discuss the challenges and benefits of on-ramping.

\section{Background: The On-Ramps into Academia Workshops}

Women with PhDs in engineering and related science fields choose industry or government positions more often than academic positions ${ }^{[3]}$. According to the NSF, in $2012,23 \%$ of female $\mathrm{PhDs}$ in engineering and related science fields worked in business/industry; $9 \%$ were selfemployed; $9 \%$ worked in non-profit organizations; and 11\% worked for federal, state or local governments $^{[6]}$. Women comprise only $19 \%$ of full-time, full professors in engineering and related science fields nationwide ${ }^{[7]}$. A common recruitment strategy for hiring female faculty in STEM is to hire women from other universities. This strategy fails to increase the number of female faculty nationally. An alternative recruitment strategy, explored in this research, is to encourage female PhDs in industry and government positions to make the transition to academia. This career path is not common in engineering, indeed we only found one paper on nonacademic-to-academic career transitions in engineering and related science fields ${ }^{[9]}$.

In 2008, the University of Washington's ADVANCE Center for Institutional Change received a National Science Foundation ADVANCE PAID grant called "On-Ramps into Academia." The goal of On-Ramps into Academia was to increase the pool of women faculty available to all universities by providing professional development to $\mathrm{PhD}$-level women in industry or research laboratories who were seeking to transition into faculty careers. The recruitment of participants 
was difficult and consisted of emails to listservs, individual invitations, and word-of-mouth. Most women who fit the criteria and applied were invited to the workshops. Three two-day OnRamps into Academia workshops were held every 18 months (in 2009, 2011, and 2012). The On-Ramps program provided practical tools and support to 67 women who were interested in making the transition to academia. Women at all stages of the transition to academia were invited to attend, but were required to be a minimum of three years past their $\mathrm{PhD}$ and/or postdoctoral position. The workshop participants were employed in industry or government careers at the time of their application to the workshops.

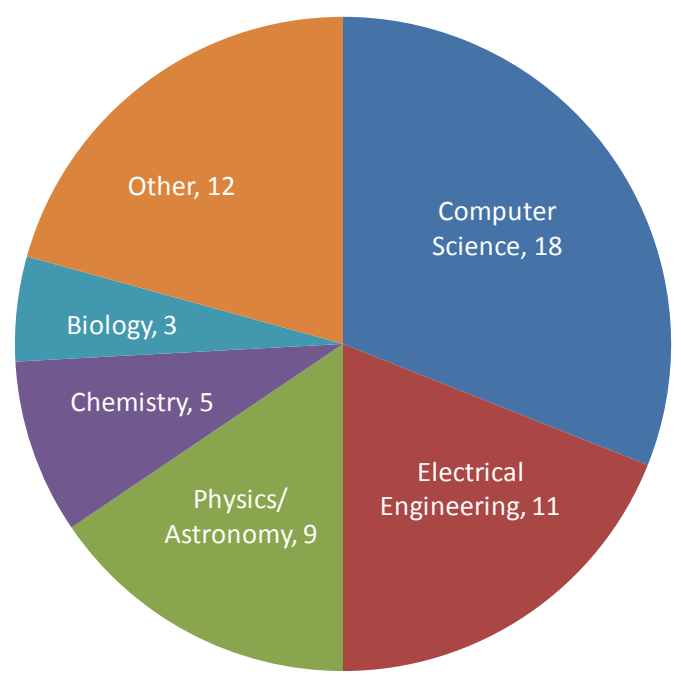

Figure 1: Academic fields of On-Ramps Participants. Other includes Materials Science and Engineering, Chemical Engineering, Atmospheric Sciences, Mathematics, Mechanical Engineering, Environmental Engineering, Industrial Engineering, Human-Computer Interaction, Geochemistry, Fish Ecology, Marine Conservation, Anatomy, and Medicine, which each had one or two participants.
Of the participants, fields with the highest representation among OnRamps workshop participants were: Computer Science (30\%), Electrical Engineering (18\%), Physics and Astronomy (15\%), Chemistry $(8 \%)$, and Biology $(5 \%)$. Each of the following fields was represented by one or two On-Ramps participants: Chemical Engineering, Materials Science and Engineering, Atmospheric Sciences, Mathematics, Mechanical Engineering, Environmental Engineering, Industrial Engineering,

Human-Computer Interaction, Geochemistry, Fish Ecology, Marine Conservation, Anatomy, and Medicine (Figure 1).

Nearly 30 speakers presented at the workshops. Speakers represented faculty from a wide range of institutions from primarily undergraduate institutions to very high research institutions ${ }^{[1]}$. Almost all of the speakers are female faculty members who had started their careers in industry or research labs and successfully transitioned to academia. They provided encouragement and role models to the participants and demonstrated that a transition to academia was possible. Topics included translating industry skills and research to an academic setting; building a research and teaching program; discussing why working in academia is rewarding; balancing work and family in academia; and crafting a research statement, a teaching statement, and curriculum vitae (CV) for an academic audience (Table 1). Topics were suggested during research with women faculty who had begun their careers in industry or research labs. Faculty 
members from UW participated in sessions to provide participants with one-on-one advice on their CVs. During the On-Ramps workshops, participants had opportunities for networking and informal discussions with peers and current faculty. Speaker presentations and workshop handouts are archived on the On-Ramps into Academia workshop website: http://www.engr.washington.edu/onramp/. Program staff members continue to maintain contact with workshop attendees through email and private On-Ramps established listservs. The program also shared faculty job posting announcements through an RSS feed.

\section{On-Ramps into Academia Workshop}

\begin{tabular}{|c|c|c|c|}
\hline & Day 1 & Day 2 & Day 3 \\
\hline 8:00 am - 9:00 am & & Welcome breakfast & Breakfast \\
\hline 9:00 am - 10:30 am & & $\begin{array}{c}\text { Why Academe Wants } \\
\text { You }\end{array}$ & The Interview Process \\
\hline 10:30 am - 10:45 am & & Break & Break \\
\hline 10:45 am - 11:45 am & & $\begin{array}{l}\text { Preparing for } \\
\text { Academia }\end{array}$ & $\begin{array}{c}\text { Building Your } \\
\text { Teaching Program }\end{array}$ \\
\hline 11:45 am - 1:00 pm & & Lunch & Lunch \\
\hline 1:00 pm - 2:00 pm & & $\begin{array}{l}\text { Leadership in } \\
\text { Academia }\end{array}$ & $\begin{array}{c}\text { Building Your } \\
\text { Research Program }\end{array}$ \\
\hline 2:00 pm - 3:00 pm & & $\begin{array}{c}\text { Work/Life Flexibility as } \\
\text { Faculty }\end{array}$ & $\begin{array}{c}\text { Keeping Ties with } \\
\text { Industry }\end{array}$ \\
\hline 3:00 pm - 4:00 pm & & travel & $\begin{array}{l}\text { Discussion and } \\
\text { Conclusion }\end{array}$ \\
\hline 4:00 pm - 5:30 pm & & $\begin{array}{c}\text { Interactive CV } \\
\text { Workshop }\end{array}$ & \\
\hline 5:30 pm - 6:30 pm & & Networking Reception & \\
\hline 6:30 pm - 8:00 pm & Mentoring Dinner & & \\
\hline
\end{tabular}

Table 1: Sample On-Ramps into Academia Workshop Aqenda.

To date, twelve women who attended an On-Ramps workshop have transitioned to faculty careers at universities all over the US. Three of these women are underrepresented minorities (URMs). Another two women are in PhD-level staff positions in academia, both of whom are URMs. At least one more woman is actively seeking an academic job as of 2015 and has had interviews. Some participants decided that academia was not for them and others have applied to academic positions and not been hired as faculty.

\section{Interviews: Studying the Impact of the On-Ramps into Academia Workshops}

To understand "on-ramping" from the perspectives of the women who had successfully transitioned to academia, we interviewed the first ten On-Ramps workshop participants to secure academic jobs. We used ethnographic methods to collect and analyze semi-structured interviews about their experiences. Interviews were audio recorded if permission was given by the participant; interviews lasted between 40 minutes and 2 hours; and they were conducted inperson, or over Skype when an in-person interview was not possible. The second author conducted all interviews over a 10-month period. The transcription process was contracted out to a third party, but the second author checked each transcription for fidelity to the audio recording 
(when one was available) and made any necessary corrections, including retaining the participant's natural inflections, and correcting any word errors. All data in the transcripts were made anonymous.

We used axial coding to analyze our data ${ }^{[4,2,8]}$. The first and second authors worked together to complete an open code process. Next, we refined these codes into categories; questioned the relevancy of variables; and identified emerging themes. We used participants' own terms in constructing codes and identifying themes. After the first and second authors' initial analysis was completed, they debriefed with the other authors who had run the workshops. The process of team memo-ing was repeated several times in the course of data analysis. The participants had an opportunity to review their transcript data that were used in the context of the paper. Member checking and peer debriefing among colleagues and participants help ensure the trustworthiness of our interpretations ${ }^{[5]}$. From the interviews, we found that the personalized advice and practical tools the women received at On-Ramps into Academia helped them translate their skills and experiences for academic search committees. In addition, the major reward sought by these ten faculty members was the ability to leverage their nonacademic career skills to effect change in the academic context.

At the same time, our data revealed three core barriers that can influence the viability of transitioning to academia, particularly for women. These were the challenges of communicating the value of nonacademic career skills in the academic context; the financial costs of the transition; and gender discrimination.

First, we learned that the women found it difficult to communicate the value of their nonacademic career experiences in the academic context. This was more challenging for women in corporate jobs because they were less likely to have published their research. Many participants believed that the faculty career must follow a linear path from graduate school to tenure track. One participant from government research had heard from peers that she had missed her opportunity to be a professor: "And I knew it was hard, because you hear a lot of things where people say it's a one-way street. Once you go into industry you can never go back."

Second, participants were concerned about financial impacts of entering academia and indeed, several participants did accept a lower salary, sometimes significantly lower, at their faculty job. A second participant reported, "When I got the final number [pay rate] it was such a shock [...] I reduced my salary by one-third and I'm working much harder because I have to prepare all these courses that I have never taught." The first participant echoes, "So taking a step down when you start in a new field ... it's something that, it's not easy."

Third, all participants experienced gender discrimination as students in academia. This posed a barrier to their confidence regarding on-ramping back into this environment. The On-Ramps into Academia workshop not only exposed our participants to role models who had successfully made the transition to academia but also provided critical information about academia. 
Participants reported that On-Ramps helped them both logistically and emotionally, thus facilitating their transition into faculty positions. A third participant said that the workshop helped her to feel confident that, despite gender discrimination, she could transition to academia on the merits of her scientific credentials: "My main take-away that I really liked was...I should feel proud to be a woman. I should not have to apologize for not being a man."

On-Ramps into Academia workshop bridged the wide gap between participants' initial doubts about transitioning into academia and their strong feelings of success and accomplishment in their new careers. All of our participants contemplated a career transition, but, before the OnRamps into Academia programmatic intervention, most doubted it was possible. Once they had successfully transitioned into faculty positions, our data showed that participants expressed high levels of confidence in their abilities, value and contributions, especially in educating the next generation of scientists and engineers.

\section{Summary: Implications of On-Ramps}

The competition over excellent women faculty in science and engineering is, nationally, a zerosum game. It is not uncommon to hear faculty say things like, "Let's see if we can hire away Professor Jones from University X - she's a star!" This type of attitude results in a shell game of female faculty moving from one institution to the next and does not expand the national pool of female faculty in STEM.

On-Ramps into Academia brought light to a new potential pool of faculty applicants, both female and male. Our data from our interviews suggest that "on-ramping" can create a new pool of highly qualified candidates to help diversify the faculty in science and engineering. Indeed, one participant summarized the impact of her career experiences on the classroom: "I think everything, practically, every single session I teach, that within a minute or two, I can link it to real life." Another seconded this: "The field has moved so far in industry, that there is a huge gap now....we could complete the cycle of student learning by having people from industry seed the next generation of scientists with the skills that industry needs to move forward." A limitation of our study is that it only focused on women. A future research project could include interviewing women and men who have successfully made the transition to academia without attending an On-Ramps workshop. Our findings have implications for alternative hiring and recruitment practices in higher education.

\section{Acknowledgments}

The authors would like to thank the interview participants. This work was supported by the National Science Foundation under grants HRD-0819407 and EEC-1136916. Any opinion, finding, and conclusion or recommendations expressed in this material are those of the authors and do not necessarily reflect the views of the National Science Foundation. 


\section{References}

1. Carnegie Foundation for the Advancement of Teaching. (2001). The Carnegie Classification of Institutions of Higher Education: 2000 edition. Retrieved March 31, 2011 from http://classifications.carnegiefoundation.org/resources.

2. Glaser, B. G., \& Strauss, A. L. (1967). The Discovery of Grounded Theory: Strategies for Qualitative Research. Chicago: Aldine Pub. Co.

3. Hoffer, T. B., Hess, M. D., Welch, V., \& Williams, K. (2007). Doctorate Recipients from United States Universities: Summary Report 2006. Chicago, IL.

4. Martin B., \& Hanington BM. (2012) Universal Methods of Design: 100 Ways to Research Complex Problems, Develop Innovative Ideas, and Design Effective Solutions. Rockport Publishers

5. Miles, M. B., \& Huberman, A. M. (1994). Qualitative Data Analysis: An Expanded Sourcebook. Thousand Oaks, CA: Sage Publications.

6. National Science Foundation, \& National Center for Science and Engineering Statistics. (2012). Characteristics of Doctoral Scientists and Engineers in the United States: 2008 (pp. 1-83). Arlington, VA. Retrieved from http://www.nsf.gov/statistics /nsf13302/.

7. National Science Foundation, \& Statistics., N. C. for S. and E. (2013). Women, Minorities, and Persons with Disabilities in Science and Engineering: 2013. Special Report NSF 13-304. Arlington, VA. Retrieved from http://www.nsf.gov/statistics/wmpd/.

8. Strauss, A. L., \& Corbin, J. M. (1998). Basics of Qualitative Research: Techniques and Procedures for Developing Grounded Theory. Thousand Oaks, CA: Sage Publications.

9. Weimer, A. W. (2001). Successfully Switch from Industry to Academia: Here's what you should know if you're considering making the transition. Chemical Engineering Progress, 97, pp. 86-95. 